\title{
NUTRITIONAL STATUS OF PEOPLE LIVING WITH HIV/ACQUIRED IMMUNODEFICIENCY SYNDROME - A CROSS-SECTIONAL STUDY
}

\author{
RAVISHEKAR N HIREMATH ${ }^{1 *}$, SHAILAJA S PATIL ${ }^{2}$, ARUN K YADAV ${ }^{3}$ \\ ${ }^{1}$ Department of Community Medicine, BLDEA's University, Shri BM Patil Medical College, Bijapur - 586 103, Karnataka, India. ${ }^{2}$ Prof and \\ HOD, Department of Community Medicine, BLDEA's University, Shri BM Patil Medical College, Bijapur - 586 103, Karnataka, India. ${ }^{3}$ Asst \\ Prof, Department of Community Medicine, Armed Forces Medical College, Pune, Maharashtra, India. Email: drshekar80@gmail.com
}

Received: 13 January 2018, Revised and Accepted: 11 May 2018

ABSTRACT

Objective: The objective of this study was to assess the nutritional status of people living with HIV and acquired immunodeficiency syndrome (PLHAs) on antiretroviral treatment (ART) and their knowledge with respect to role of nutrition in maintaining their health and to know the association of various factors with nutritional status and knowledge among PLHAs attending ART centers.

Methods: A cross-sectional study carried out at ART center of a tertiary care institution in Maharashtra. A total of 104 PLHAs who were started on ART for the $1^{\text {st }}$ time and completed minimum 6 months of treatment and who gave consent were included in the study. Data were collected by personal interview technique after taking informed consent with the help of pre-tested, prevalidated questionnaire with predetermined scoring system along with anthropometric measurements and relevant investigations maintaining strict confidentiality. Those with $<50 \%$ scores were marked as unsatisfactory and more than $50 \%$ as satisfactory. Data were entered into Excel Sheet and were analyzed with SPSS 17.1 software.

Results: In our study, $51.92 \%$ of the study participants were female, mean age was $38.5 \pm 9.6,14.42 \%$ were illiterate, $32 \%$ had undergone primary education, and equally had secondary education. 16.35\% were drivers and almost all were married (96.15\%). Mean hemoglobin (Hb\%) before and after ART was $10.45 \pm 2.13$ and 10.64 \pm 2.16 , while mean CD4 count before and after ART was $177.26 \pm 146.52$ and $413.69 \pm 266.25$, respectively, while post-ART mean body mass index (BMI) was 20.55 \pm 3.07 . Majority (75\%) were on ART for more than 12 months. Majority (65.38\%) had unsatisfactory score with respect to overall knowledge regarding nutrition. $28.85 \%$ were underweight and $2.88 \%$ obese; while $17.31 \%$ were overweight and rest were normal. 46.15\% were anemic. Statistical significant difference was noted among age, educational status, marital status, knowledge score, and anemia status with respect to BMI. Logistic regression with BMI as an outcome showed that age binary had some association. It means that there are 2.7 times odds of normal BMI in higher age group. Statistically significant difference was also noted in mean CD4 count before and after ART therapy. Regression analysis showed that CD4 count post-ART depends on pre-ART CD4 count, ART duration, and gender of the individual. With each unit increases in pre-ART CD4 and ART duration, there is increase of 0.44 and 4.5 units in after ART CD4. Post-ART CD4 count increased more among females compared to males in our study.

Conclusion: There exists a wide gap in PLHAs knowledge regarding nutritional aspects. The study also shows that good nutrition has good influence on CD4 count. PLHAs belonging to higher age 40 years, married, and educated, those who had better knowledge score and good Hb\% had better nutrition. Therefore, there is an urgent need for nutritional interventions like frequent health educational sessions on nutrition to increase the knowledge of PLHAs can be emphasized during each follow-up visit at ART centers. There is a need to identify PLHAs with no or minimum nutritional support and provides nutritional supplementation, for which planning and policy section needs adequate research evidences from India.

Keywords: Nutrition, HIV/acquired immunodeficiency syndrome, Knowledge, CD4.

(C) 2018 The Authors. Published by Innovare Academic Sciences Pvt Ltd. This is an open access article under the CC BY license (http://creativecommons. org/licenses/by/4. 0/) DOI: http://dx.doi.org/10.22159/ajpcr.2018.v11i7.24749

\section{INTRODUCTION}

Wide-ranging serious health, economic, and social problems have been implicated by HIV/acquired immunodeficiency syndrome (AIDS) for people living with HIV/AIDS (PLHAs) worldwide.

Introduction of combination antiretroviral therapy (cART) which is referred to as highly active ART (HAART) in 1996 has dramatically changed the course of HIV infection. Under the national AIDS control program, free antiretroviral treatment (ART) began in 2004, given to all HIV patients with CD4 count $<350$ cells/ml. HAART sustainably suppresses viral replication, allowing recovery of the immune system. As a consequence, AIDS-associated mortality and morbidity declined after the widespread introduction of HAART [1]. For those who are motivated to take therapy antiretroviral therapy (ART) and who have access to lifelong treatment, AIDS-related illnesses are no longer the primary threat [2]. However, malnutrition remains a common problem for certain subgroups of HIV-infected population on HAART such as those diagnosed late in the course of the infection and those with failed or non-adherent antiretroviral regimens [3].
HAART interrupts the replication of HIV and results not only in clinical and immune function improvement but also rapid and significant weight gain provided that the diet contains adequate energy, protein, and micronutrients to enable nutritional recovery. On the other side, poor nutrition can lead to reduced immunity, increased susceptibility to disease, impaired physical and mental development, and reduced productivity [4]. Moreover, reduced body mass index (BMI) is still predictive of mortality even with antiretroviral treatment and highlights the value of appropriate nutritional monitoring and support in addition to antiretroviral medications. Furthermore, reduced food intake can reduce the efficacy of antiretroviral treatment regimens, as some drugs may not be properly absorbed or can cause significant side effects if not taken with adequate food. Adequate good quality food intake largely depends on the nutrition awareness level of PLHAs and socioeconomic factors. Results from studies among HIV-infected adults in Haiti, Kenya, Malawi, and Zambia have demonstrated significant positive effects of macronutrient supplementation and good diet on adherence to antiretroviral medication, weight gain, and CD4 counts [5-8]. Certainly, ART has become more readily available, but nutritional status and nutritional care have long been ignored among HIV/AIDS patients 
despite the fact that malnutrition is frequently associated with the disease [9].

One of the important factors for impaired nutritional status is reduced food consumption both in terms of quantity or quality, and it may be a highly erosive "coping" strategy, as nutrient requirements rise following HIV infection. Literature available shows across the world AIDSafflicted households do tend to incur high health-care expenditures and health-care costs specific to the person with AIDS, which accounted for almost $80 \%$ of the household health-care budget and an HIV/AIDSrelated death significantly increased the probability of a household's falling below the poverty line [10].

Focus on improving nutrition status in HIV-infected patients is important because it optimizes existing immune system function, can help alleviate the burden of HIV-related complications, might reduce the overall cost of medical care, and improves the patient's quality of life [11]. Nutritional management is an essential but often neglected element in HIV care. Malnutrition not only worsens the HIV status and hastens progression to AIDS-related illnesses but also increases the chances of transmission to others particularly seen in parental to child transmission as shown in various studies [10]. Along with food insecurity, malnutrition may undermine adherence and response to ART, and exacerbate socioeconomic impacts of the virus. HIV infection itself weakens food security and compromises nutritional status by reducing work capacity and productivity, and jeopardizing household livelihoods [12]. As per the WHO also improved attention to diet and nutrition may enhance ART acceptability, adherence and effectiveness and directed countries to prepare for ART access through training on how to manage ARTs nutritional dimension [13].

Keeping in view the socioeconomic constraints particularly in resource limited settings like ours and much needed appropriate strategies for improving nutritional status; there is a need to carry out this study with the objective to assess the nutritional status of PLHAs on ART and their knowledge with respect to role of nutrition and their association with various factors if any.

\section{METHODS}

\section{Study setting}

This was a cross-sectional study carried out at ART center of a tertiary care institution in Maharashtra.

\section{Inclusion criteria}

a. PLHAs who were started on ART for the $1^{\text {st }}$ time and completed minimum 6 months of treatment.

b. Those who gave consent for participating in the study.

\section{Exclusion criteria}

a. Those who were having opportunistic infections and treatment failure, treatment defaulter's cases.

b. Pregnant ladies.

c. Those who did not give consent for participating in the study,

\section{Sampling}

Sample size of 96 was calculated keeping the expected parameter (proportion of malnutrition and PLHAs with satisfactory knowledge) at 0.5 with acceptable deviation of 0.1 on either side of truth with $95 \%$ confidence interval. Sample was collected by means of systematic random sampling taking into consideration of number of PLHAs visiting per month to cover a sample of 104 . Since all consented to be part of the study, they were included in the study.

\section{Measurement tools}

A questionnaire in local language was prepared consisting of baseline sociodemographic part, anthropometric part, certain investigations, and questions to assess the role of diet and important nutritional aspects which are important for PLHAs on ART. Accordingly, those who answered correct answers were given score 1 and wrong answers/nil answers as 0 were ever open-ended questions there marks were given as per the number of correct answers. The total score was calculated and those with $<50 \%$ scores were marked as unsatisfactory and more than $50 \%$ as satisfactory. The questionnaire was pre-tested and prevalidated and data collected by personal interview technique after taking informed consent and confidentiality maintained by coding system.

\section{Data analysis}

Data were entered into Excel Sheet and were analyzed with SPSS 17.1 software.

\section{Ethical considerations}

The study was carried out after taking institutional ethical committee clearance, and informed consent was taken from the patients and confidentiality maintained

Table 1: Sociodemographic variables of study participants

\begin{tabular}{|c|c|c|c|}
\hline \multirow{2}{*}{$\frac{\text { Variables }}{\text { Age (years) }}$} & \multirow[t]{2}{*}{ Frequency (\%) } & \multicolumn{2}{|c|}{ 95\% Conf. limits } \\
\hline & & & \\
\hline$<30$ & $17(16.35)$ & 9.82 & 24.88 \\
\hline $31-35$ & $25(24.04)$ & 16.20 & 33.41 \\
\hline $36-40$ & $27(25.96)$ & 17.86 & 35.48 \\
\hline$>40$ & $35(33.65)$ & 24.68 & 43.58 \\
\hline Total & $104(100$ & & \\
\hline \multicolumn{4}{|l|}{ Sex } \\
\hline Female & $54(51.92)$ & 41.91 & 61.83 \\
\hline Male & $50(48.08)$ & 38.17 & 58.09 \\
\hline Total & $104(100$ & & \\
\hline \multicolumn{4}{|l|}{ Education status } \\
\hline Illiterate & $15(14.42)$ & 8.30 & 22.67 \\
\hline Primary education & $34(32.69)$ & 23.81 & 42.59 \\
\hline Secondary education & $34(32.69)$ & 23.81 & 42.59 \\
\hline Intermediate & $4(3.85)$ & 1.06 & 9.56 \\
\hline Graduate and above & $17(16.35)$ & 9.82 & 24.88 \\
\hline Total & $104(100$ & & \\
\hline \multicolumn{4}{|l|}{ Occupation } \\
\hline Driver & $17(16.35)$ & 9.82 & 24.88 \\
\hline Farming & $14(13.46)$ & 7.56 & 21.55 \\
\hline Service & $4(3.85)$ & 1.06 & 9.56 \\
\hline Labor & $24(23.08)$ & 15.38 & 32.36 \\
\hline Others & $45(43.27)$ & 33.59 & 53.35 \\
\hline \multicolumn{4}{|l|}{ Residence } \\
\hline Rural & $35(33.65)$ & 24.68 & 43.58 \\
\hline Urban & $69(66.35)$ & 56.42 & 75.32 \\
\hline \multicolumn{4}{|l|}{ Marital status } \\
\hline Divorced & $1(0.96)$ & 0.02 & 5.24 \\
\hline Married & $100(96.15)$ & 90.44 & 98.94 \\
\hline Unmarried & $3(2.88)$ & 0.60 & 8.20 \\
\hline Total & $104(100)$ & & \\
\hline
\end{tabular}

Table 2: HIV positivity and art duration of study participants

\begin{tabular}{llll}
\hline $\begin{array}{l}\text { Duration of HIV } \\
\text { positivity (months) }\end{array}$ & Frequency (\%) & $\mathbf{9 5 \%}$ CI & \\
\hline$<12$ & $11(10.58)$ & 5.40 & 18.14 \\
$13-24$ & $22(21.15)$ & 13.76 & 30.26 \\
$25-48$ & $38(36.54)$ & 27.31 & 46.55 \\
$>48$ & $33(31.73)$ & 22.95 & 41.58 \\
Total & $104(100.00)$ & & \\
\hline Duration since ART & & & \\
started & & & \\
(months) & & 17.03 & 34.45 \\
\hline$<12$ & $26(25.00)$ & 12.16 & 28.13 \\
$13-24$ & $20(19.23)$ & 30.87 & 50.46 \\
$25-48$ & $42(40.38)$ & 9.06 & 23.78 \\
$>48$ & $16(15.38)$ & & \\
Total & $104(100.00)$ & & \\
\hline
\end{tabular}

ART: Antiretroviral treatment 
Table 3: Knowledge score of study participants

\begin{tabular}{|c|c|c|c|}
\hline Knowledge regarding Nutrition aspects & Frequency (\%) & 95\% C.I & \\
\hline Unsatisfactory score & 73 (70.19) & 60.43 & 78.77 \\
\hline Satisfactory score & $31(29.81)$ & 21.23 & 39.57 \\
\hline \multirow{2}{*}{\multicolumn{4}{|c|}{ Knowledge regarding general ways to stay healthy }} \\
\hline & & & \\
\hline Unsatisfactory score & $27(25.96)$ & 17.86 & 35.48 \\
\hline Satisfactory score & 77 (74.04) & 64.52 & 82.14 \\
\hline Total & $104(100)$ & & \\
\hline \multicolumn{4}{|l|}{ Overall knowledge score } \\
\hline Unsatisfactory score & $68(65.38)$ & 55.42 & 74.45 \\
\hline Satisfactory score & $36(34.62)$ & 25.55 & 44.58 \\
\hline Total & $104(100)$ & & \\
\hline
\end{tabular}

$<50 \%$ scores were marked as unsatisfactory and more than $50 \%$ as satisfactory

Table 4: Nutritional status of study participants

\begin{tabular}{llll}
\hline BMI cat & Frequency (\%) & $\mathbf{9 5 \%}$ CI & \\
\hline Underweight & $30(28.85)$ & 20.38 & 38.55 \\
Normal & $53(50.96)$ & 40.97 & 60.90 \\
Overweight & $18(17.31)$ & 10.59 & 25.97 \\
Obesity & $3(2.88)$ & 0.60 & 8.20 \\
Total & $104(100.00)$ & & \\
HB anemia cat & & & \\
Normal & $56(53.85)$ & 43.80 & 63.67 \\
Anemic & & & \\
$\quad$ Mild & $11(10.58)$ & 5.40 & 18.14 \\
$\quad$ Moderate & $21(20.19)$ & 12.96 & 29.19 \\
Severe & $16(15.38)$ & 9.06 & 23.78 \\
$\quad$ Total & $48(46.15)$ & 36.33 & 56.20 \\
Total & $104(100.00)$ & & \\
\hline
\end{tabular}

CI: Confidence interval

Table 5: Association of BMI (underweight/normal) with related factors

\begin{tabular}{ll}
\hline Associated factors & Significance (p value) \\
\hline Age & \\
$\quad$ Above/below 40 & 0.0057 \\
Gender & \\
$\quad$ Male/female & 0.4294 \\
Residing area & \\
$\quad$ Urban/rural & 0.4868 \\
Educational status & \\
$\quad$ Primary/high school and above & 0.0000 \\
Working & \\
$\quad$ Driver/non-driver & 0.3132 \\
Marital status & \\
$\quad$ Yes/no & 0.00001 \\
Knowledge score & \\
$\quad$ Sat/Unsat & 0.01083 \\
ART duration & 0.4557 \\
Duration of HIV positivity & 0.2085 \\
Anemia & \\
$\quad$ Yes/no & 0.0389 \\
\hline BMI:Body massindex &
\end{tabular}

BMI: Body mass index

\section{RESULTS}

In our study, $51.92 \%$ of the study participants were female, mean age was $38.5 \pm 9.6,14.42 \%$ were illiterate, $32 \%$ had undergone primary education, and equally had secondary education while $16.35 \%$ were graduate and above. $16.35 \%$ were drivers and only $3.85 \%$ were in government service, almost all were married (96.15\%) as shown in Table 1.

Mean hemoglobin ( $\mathrm{Hb} \%$ ) before and after ART was 10.45 \pm 2.13 and $10.64 \pm 2.16$, while mean CD4 count before and after ART was $177.26 \pm 146.52$ and $413.69 \pm 266.25$, respectively, while mean after BMI was $20.55 \pm 3.07$. $31 \%$ were HIV positive with $<12$ months duration while rest were 12 months. $25 \%$ were on ART since $<12$ months while rest were on ART for more than 12 months (Table 2). Majority (65.38\%) had unsatisfactory score with respect to overall knowledge regarding nutrition (Table 3). 28.85\% were underweight and $2.88 \%$ obese; while $17.31 \%$ were overweight and rest were normal. $46.15 \%$ were anemic as per Table 4 .

Statistical significant difference was noted among age, educational status, marital status, knowledge score, and anemia status with respect to BMI (Table 5). Logistic regression with BMI as an outcome showed that age binary had some association. It means that there are 2.7 times odds of normal BMI in higher age group.

Statistically significant difference was also noted in mean CD4 count before and after ART therapy (Table 6). Regression analysis showed that CD4 count post-ART depends on pre-ART CD4 count, ART duration, and gender of the individual. With each unit increases in pre-ART CD4 and ART duration, there is increase of 0.44 and 4.5 units in after ART CD4. Post-ART CD 4 count increased more among females compared to males in our study.

\section{DISCUSSION}

Better nutritional status help PLHAs to remain healthy and strengthen the immune system, so as to have a significant impact in maintaining and improving clinical condition. Assessment of nutritional status in PLHAs is of paramount importance and will form basis to appropriately plan continuum of care for PLHAs and helps in monitoring efficacy of ART.

As per the study carried out by Sicotte et al. [14], on two West African cohorts, at baseline, low BMI was associated with low Hb levels and CD4 counts, while anemia was associated with low CD4 counts and more in females. While treatment contributed to early gains in BMI, $\mathrm{Hb}$, and albumin in the first 6 months of treatment, initial improvements plateaued or subsided thereafter. Despite HAART, malnutrition persisted in both cohorts after 1 year, especially in those who were anemic, hypoalbuminemic or had a low BMI at baseline [14] which is similar to our study findings.

Anand and Puri[15], carried out a study among 400 PLHAs on ART in India, showed the mean BMI of the study sample was $19.73 \pm 3.55 \mathrm{~kg} / \mathrm{m}^{2}$ with around $40 \%$ having BMI $<18.5 \mathrm{~kg} / \mathrm{m}^{2}$ while in our study $28.85 \%$ were underweight. The same study by Anand and Puri also showed that all anthropometric measurements were found to correlate positively and significantly with CD 4 count $(\mathrm{p}<0.05)$. These findings are consistent with our study. Similarly, Sachdeva [16] in North India carried out a study among 100 PLHAs on ART and showed that the mean weight and BMI of the participants were $58.6 \pm 11.7$ (range, 34-94) $\mathrm{kg}$ and $21.5 \pm 3.7$ (range, $13.6-36.7$ ) $\mathrm{kg} / \mathrm{m}^{2}$, respectively, which was more when compared our study (mean weight $=51.31 \pm 9.39$ with range from 28 to 75 and mean $\mathrm{BMI}=20.55 \pm 9.4$ with range from 13.84 to 28.99 ).

While Thapa et al. [17] in Nepalese population showed that $19.93 \%$ of the PLHAs visiting the ART centers in Kathmandu valley were undernourished. Illiteracy, residence in care homes, CD4 cell count 
Table 6: Association of $\mathrm{CD} 4$ counts before and after initiation of art

\begin{tabular}{llllll}
\hline Variable & Observations & Mean & SE & SD & (95\% Confidence interval) \\
\hline CD4 count before ART & 104 & 177.2692 & 14.36761 & 146.5214 \\
CD4 count after ART & 104 & 413.6923 & 26.10875 & 266.2581 \\
\hline
\end{tabular}

Paired t-test, $\operatorname{Pr}(|\mathrm{T}|>|\mathrm{t}|)=0.0000$. SE: Standard error, SD: Standard deviation

$<350$ cells $/ \mathrm{mm}^{3}$, opportunistic infections, and illness at the WHO clinical stages III and IV were found to be significant predictors of undernutrition.

A study carried out by Hadgu et al. [18] in Ethiopia, the prevalence of undernutrition was $42.3 \%$ (95\% confidence interval [CI]: 37.4\%$47.3 \%$ ). Of which $12 \%$ were severely undernourished and $10 \%$ and $20.3 \%$ belonged to moderate and mild undernutrition category, respectively. The prevalence of wasting was 75\% (95\% CI: 70.4\%$79.2 \%$ ). Severe wasting was observed in $\sim 27 \%$ of respondents. In multivariate analysis, the same study also showed household food insecurity (adjusted odds ratio $[\mathrm{AOR}]=1.85$; 95\% CI 1.16, 2.86), inadequate dietary diversity (AOR=1.19; $95 \% \mathrm{CI} 1.08,1.75)$, anemia (AOR=1.67; 95\% CI 1.05, 2.65), and absence of nutritional support ( $\mathrm{AOR}=0.34,95 \% \mathrm{CI} 0.22,0.54$ ) were found to be independent predictors of undernutrition [18]. In comparison, our study showed only $28.85 \%$ undernutrition, and age, educational status, marital status, knowledge score, and anemia status had impact on BMI [Table 5].

As per our study with predetermined scoring system, although $74.04 \%$ had satisfactory score with respect to knowledge regarding general ways to say healthy, only $29.81 \%$ had satisfactory score with respect to knowledge regarding nutrition aspects with only $34.62 \%$ having overall satisfactory score. The overall knowledge score had statistically significant relation with BMI. All the above-quoted studies could not quantify the knowledge assessment among PLHAs.

\section{Limitations}

Our study being a cross-sectional in design does not allow us to generalize these results. Some important predictors such as household food insecurity, job insecurity, and data on nutrition intake were not considered in our study due to time constraints and feasibility in conducting interviews with huge number of patients attending ART center in a tertiary care hospital. Longitudinal follow-up/prospective design will give more information about predictors of malnutrition among PLHAs.

\section{CONCLUSION}

There exists a wide gap in PLHAs knowledge regarding nutritional aspects. The study also shows that good nutrition has good influence on CD4 count. PLHAs belonging to higher age 40 years, married, and educated, those who had better knowledge score and good $\mathrm{Hb} \%$ had better nutrition. Therefore, there is an urgent need for nutritional interventions like frequent health educational sessions on nutrition to increase the knowledge of PLHAs can be emphasized during each follow-up visit at ART centers. There is a need to identify PLHAs with no or minimum nutritional support and provides nutritional supplementation, for which planning and policy section needs adequate research evidences from India.

\section{AUTHOR'S CONTRIBUTION}

Dr. RN Hiremath and Dr. Shailaja Patil were involved in planning, conducting, analysis, and manuscript preparation. Dr. AK Yadav was involved in methodological, analysis, and manuscript editing and corrections of the manuscript as per journal requirement.

\section{CONFLICTS OF INTEREST}

The authors declare that they have no conflicts of interest.

\section{REFERENCES}

1. Palella FJ Jr., Delaney KM, Moorman AC, Loveless MO, Fuhrer J, Satten GA, et al. Declining morbidity and mortality among patients with advanced human immunodeficiency virus infection. HIV outpatient study investigators. N Engl J Med 1998;338:853-60.

2. Begum SK, Kavuri NS, Uppalapati MC, Polavarapu D. Assessment of the nutritional behavior among college students-a survey. Int J Pharm Pharm Sci 2018;10:46-9.

3. Wanke CA, Silva M, Knox TA, Forrester J, Speigelman D, Gorbach SL, et al. Weight loss and wasting remain common complications in individuals infected with human immunodeficiency virus in the era of highly active antiretroviral therapy. Clin Infect Dis 2000;31:803-5.

4. Kolgiri V, Patil VW, Nagar V. Correlation of total antioxidant status (TAS) with DNA damage In HIV/AIDS patients. Int J Pharm Pharm Sci 2016;8:240-4.

5. Ivers LC, Chang Y, Gregory Jerome J, Freedberg KA. Food assistance is associated with improved body mass index, food security and attendance at clinic in an HIV program in central haiti: A prospective observational cohort study. AIDS Res Ther 2010;7:33

6. Tirivayi N, Koethe J, Groot W. Clinic-based food assistance is associated with increased medication adherence among HIV infected adults on long-term antiretroviral therapy in Zambia. J AIDS Clin Res 2012;3:171.

7. Ndekha MJ, van Oosterhout JJ, Zijlstra EE, Manary M, Saloojee H, Manary MJ, et al. Supplementary feeding with either ready-to-use fortified spread or corn-soy blend in wasted adults starting antiretroviral therapy in malawi: Randomised, investigator blinded, controlled trial. BMJ 2009;338:b1867.

8. Gichunge C, Hogan J, Sang E, Sidle J. Role of Food Assistance in Survival and Adherence to Clinic Appointments and Medication among HIV-Infected Patients on Antiretroviral Therapy (ART) in Western Kenya. Vienna: XVIII International AIDS Conference; 2010.

9. Núñez-Rocha GM, Wall KM, Chávez-Peralta M, Salinas-Martínez AM, Benavides-Torres RA. Nutritional care, time period since diagnosis, demographics and body mass index in HIV/AIDS patients. Rev Invest Clin 2013;65:291-9.

10. HIV/AIDS and Food and Nutrition Security. Available from: http:// www.ifpri.org/sites/default/files/pubs/pubs/fpreview/pv07/pv07.pdf. [Last accessed on 2014 Mar 25].

11. Sachdeva RK, Sharma A, Wanchu A, Dogra V, Singh S, Varma S, et al. Dietary adequacy of HIV infected individuals in north india - a crosssectional analysis. Indian J Med Res 2011;134:967-71.

12. Castleman T, Seumo-Fosso E, Cogill B. Food and Nutrition Implications of Antiretroviral Therapy in Resource Limited Settings. Washington, D.C: Food and Nutrition Technical Assistance Project (FANTA) Academy for Educational Development; 2004. Report No.: 7. Available from: http://www.fantaproject.org/publications/tn7.shtmlwebcite. [Last accessed on $2014 \mathrm{Mar}]$.

13. Nutrient Requirements for People Living with HIV/AIDS Report of a Technical Consultation. Available from: http://www.who.int/nutrition/ publications/Content nutrient requirements.pdf. [Last accessed on 2014 Mar 25].

14. Sicotte M, Bemeur C, Diouf A, Zunzunegui MV, Nguyen VK. Nutritional status of HIV-infected patients during the first year HAART in two West African cohorts. J Health Popul Nutr 2015;34:1

15. Anand D, Puri S. Anthropometric and nutritional profile of people living with HIV and AIDS in India: An assessment. Indian J Community Med 2014;39:161-8.

16. Sachdeva RK. Dietary adequacy of HIV infected individuals in north India - A cross-sectional analysis. Indian J Med Res 2011;134:967-71.

17. Thapa R, Amatya A, Pahari DP, Bam K, Newman MS. Nutritional status and its association with quality of life among people living with HIV attending public anti-retroviral therapy sites of Kathmandu valley, Nepal. AIDS Res Ther 2015;12:14.

18. Hadgu TH, Worku W, Tetemke D, Berhe H. Undernutrition among HIV positive women in Humera hospital, Tigray, Ethiopia, 2013: Antiretroviral therapy alone is not enough, cross sectional study. BMC Public Health 2013;13:943. 